\title{
Epidemiology of orthopedic trauma admissions over year 2017 in the General Hospital H+ in Queretaro Mexico
}

Background: The dynamics of demography in México is changing and its population is aging. Osteoporotic and fragility fractures are diseases associated with aging and therefore its incidence is expected to grow accordingly.

Methods: We conducted a retrospective study of epidemiological data contained on medical records of 50 years and older patients with fracture admitted over a 12-month period at the Orthopedic Service from the General Hospital H+ in Queretaro Mexico. Descriptive and inferential statistics methods for distribution of patients according to gender and age group were used. Qualitative variables were presented by distributions of absolute and relative frequencies and distributions assessed by chi-square method.

Results: From 150 patients presented in the Emergency Unit, 32 patients were admitted in Orthopedic Service. Data of 32 medical records showed the most common age groups was 50 to 59 (male 44.4\% female 34.8\%). The more frequent factures were in upper limbs (male 33.3\% - female 47.8\%), hip (male $11.1 \%$ - female $21.7 \%$ ) and spinal bone (male $11.1 \%$ - female $4.3 \%$ ). Most common mechanism of trauma was fall (male $44.4 \%$ - female $56.5 \%$ ) where no less than $50 \%$ of patients had pre-existing illness (systemic arterial hypertension, Diabetes Mellitus II, Obesity, Smoking and alcoholism) as predisposition factors to factures. Only one patient was diagnosed with OP using BMD and only one patient received treatment for OP.

Conclusion: The frequency of patients with the most common type and trauma mechanism of fractures admitted in the Orthopedic Unit was consistently increased in female than male gender and correlates with previous reports. It was noticed that exists a medical management of patients related to reliable diagnosis and timely treatment of fracture fragility and $\mathrm{OP}$, not according to criteria issued by international health entities.

Keywords: orthopedic trauma • epidemiological studies $•$ demography $•$ fragility fractures

\section{Introduction}

Similar to others world regions, the dynamics of demography in México is changing and its population is getting older [1]. The current life expectancy at birth in México is the 76 years (increased 40 years the last 7 decades) and the population of the age group of 60 years and over, will increase from 13 million (10\% in 2018), up to 32 million $(21 \%$ by 2050$)$. At that time, the average life expectancy of Mexico will be 81 years. Consequently and given that osteoporotic and fragility fractures are diseases associated with aging, their incidence is expected to grow accordingly. It is estimated that the current population of Mexico is 126 million habitants, of which $16 \%$ (20 million) is represented by people 50 years of age or older and 4.2\% (5 million) by persons of 70 years or older. By the year 2050, it is estimated that 30\% (45 million) of the population will exceed 50 years and $10 \%$ (16 million) will be 70 years or older, while the total population will reach 150 million [1].

Epidemiology of osteoporosis (OP) in Mexico

Epidemiological studies have reported the burden of hip and vertebral fractures in Mexico [2,3]. It was published in 2005 that 1 in 12 Mexican women and 1 in 20 Mexican men will undergo a hip fracture after the age of 50. Therefore in Mexico the life-time probability of having a hip fracture at 50 years of age was $8.5 \%$ in Mexican women and 3.8\% in Mexican men [4].

\author{
Jose L. Carrillo-Gamboa* \& \\ Alfonso Martinez-Flores \\ Department of Traumatology and \\ Orthopedic Surgery, Regenerative \\ Medicine Center, Queretaro, Mexico \\ *Author for correspondence: \\ joelouicarrillo@gmail.com
}


Between the years 2000 and 2006, the age-specific incidence of hip fracture increased significantly both for men and women by $1 \%$ per year [2]. The numbers of hip fractures reported in 2005 were $29,732,68 \%$ of which were found in women. Assuming no change in the age- and sex-specific incidence of hip fracture, the number of hip fractures was expected to increase markedly with time to 155,874 in 2050 . However, assuming that the age-specific incidence continues the number of hip fractures in men and women would increase by a further $46 \%$ to 226,886 in 2050 [2]. Under this scenario Mexico presents an intermediate rate of hip fractures in comparison to other countries; the highest rates are recorded in Sweden, USA and the lowest rates in China and Turkey [5].

The prevalence rate of vertebral fracture for Mexicans over 50 years of age has been reported on $19.2 \%$ for women and $9.8 \%$ for men $[6,7]$. The vertebral fractures increase with the age in both genders, and as occurs in many others countries, the vertebral fractures are largely undiagnosed. The incidence of other fragility fractures reported in 2005 by the Mexican Institute of Social Security (IMSS) shown that wrist fractures were the most common reported fracture in persons aged 50 and older, followed by hip, humerus, and pelvis fractures [3].

\section{Prevalence OP in Mexico}

A performed study in 2000 discovered that exist a significant variation of the bone mineral density (femoral and lumbar spine of 4,460 women from urban areas between 20 and 69 years old) in different geographic regions of Mexico [8]. A completed community-based study, carry out in 2003 including 400 women from the southeast of Mexico, showed a prevalence of vertebral fractures of $19.35 \%$ in women 50 years and older [9]. In 2006 a study was carried out in a sample of 408 men and 400 women with bone mineral density (BMD), performed by dualenergy X-ray absorptiometry, according to the operational criteria for OP issued by the World Health Organization (WHO). The results in the lumbar spine revealed that $9 \%$ and $17 \%$ of men and women respectively had OP and that 30\% and $43 \%$ of men and women had osteopenia respectively. At the femoral neck, OP was found in $6 \%$ of men and $16 \%$ of women, and osteopenia in $41 \%$ men and $56 \%$ of women in the same sample [10].

As a consequence of aging and the associated increase in fractures by OP and bone fragility, the current work aimed to review epidemiological data and the medical management followed in the General Hospital H+ from Queretaro Mexico, referent to suspect and treating of osteoporosis and fragility fractures in the age group of patients with high risk. With the data obtained, we want to start a campaign of awareness and training of the medical community, responsible for the treatment of fractures due to OP and consequently implement preventive actions for benefit of the patients.

\section{Materials and Methods}

We performed a retrospective study of patients admitted at the Emergency Service from the General Hospital $\mathrm{H}+$ (private institute) in Queretaro Mexico, from January to December 2017. From the total of medical records integrated (correspondent to 150 patients presentation) in this period, only those medical records correspondent to patients with fractures admitted in the Orthopedic Service were considered for this study. The epidemiological data of orthopedic patients admitted were recorded in a form with eight items: gender, age, location of injury, mechanism of trauma injury, medical treatment, bone mineral densitometry (BMD), mention and treatment for OP.

The patients were selected according to the age groups established by the WHO, as adult (19 to 59 years) and elderly (60 years or over), and were subsequently classified by decades and gender for analysis.

The location of injury was classified into upper limb fractures, lower limb fractures, hip, spinal bone and others. Mechanism of trauma injury was considered as the causing factor of fractures and included predisposition factors.

The distribution of patients according to gender and age group from a sample of 32 orthopedic patients was performed by descriptive and inferential statistics methods. Qualitative variables were presented by distributions of absolute and relative frequencies. The distribution of variables was assessed by the chi-square method with a significant level alpha $=0.05$ for rejection of the null hypothesis. All statistical analysis was performed by a validated Excel Sheet (Microsoft Excel 2016).

\section{Results}

The analysis of patient presentations during the year from January 2017 through to December 2017 showed that of a total of 150 patients 
presented in the Emergency Service, there were 32 patients with fractures admitted under the Orthopedic Service. The average age of orthopedic patients was 66 years and the genre proportion was of 28:72 male to female. Hence the general prevalence of fractures obtained in this study was male $6 \%$ and female $15 \%$.

From 32 medical records analyzed nine (28\%) were males and $23(7 \%)$ were females Table 1 . In both male and female gender, the most common age group was 50 to 59 (44.4\% male - $34.8 \%$ female). This difference between genders was not considered significant $\left(\mathrm{X}^{2} \mathrm{p}>0.05^{*}\right)$.

In relation to the anatomical location of injury, from 32 medical records reviewed, 14 patients (44\%) suffered upper limb injuries and 7 patients $(22 \%)$ suffered lower limb injury Table 2. Among the genre, the most common trauma causing admission was due to injury located in Upper limbs with $33 \%$ in male and $47.8 \%$ in female respectively. This difference between genders was not considered significant $\left(\mathrm{X}^{2}\right.$ $\left.\mathrm{p}>0.05^{*}\right)$.

Table 1. Distribution according to gender and age group of orthopedic patients treated at the General Hospital H+ Queretaro Mexico, from January to December 2017

\begin{tabular}{|c|c|c|c|c|}
\hline \multirow{2}{*}{ Age } & \multicolumn{2}{|c|}{ Male } & \multicolumn{2}{|c|}{ Female } \\
\hline & $\mathbf{N}$ & $\%$ & $\mathbf{N}$ & $\%$ \\
\hline 40 to 49 & 0 & 0 & 2 & 8.7 \\
\hline 50 to 59 & 4 & 44.4 & 8 & 34.8 \\
\hline 60 to 69 & 1 & 11.1 & 3 & 13 \\
\hline 70 to 79 & 2 & 22.2 & 7 & 30.4 \\
\hline 80 to 89 & 2 & 22.2 & 2 & 8.7 \\
\hline 90 to 99 & 0 & 0 & 1 & 4.4 \\
\hline Total & 9 & 100 & 23 & 100 \\
\hline
\end{tabular}

Table 2. Distribution of gender according to the anatomical location of injury of orthopedic patients admitted at the General Hospital H+ Queretaro Mexico, from January to December 2017

\begin{tabular}{|c|c|c|c|c|}
\hline \multirow{2}{*}{$\begin{array}{l}\text { Location of } \\
\text { Injury }\end{array}$} & \multicolumn{2}{|c|}{ Male } & \multicolumn{2}{|c|}{ Female } \\
\hline & $\mathbf{N}$ & $\%$ & $\mathbf{N}$ & $\%$ \\
\hline Upper limb & 3 & 33.3 & 11 & 47.8 \\
\hline Lower limb & 2 & 22.2 & 5 & 21.7 \\
\hline Hip & 1 & 11.1 & 3 & 21.7 \\
\hline Spinal bone & 1 & 11.1 & 1 & 4.3 \\
\hline others & 2 & 22.2 & 1 & 4.3 \\
\hline Total & 9 & 100 & 23 & 100 \\
\hline $\begin{array}{l}\text { Font: medical re } \\
p>0.05^{*}, X^{2} \text { test }\end{array}$ & & & & \\
\hline
\end{tabular}

In reference to trauma mechanisms, the most frequent was fall with $44.4 \%$ male and $56.5 \%$ female Table 3. This difference between genders was not considered significant $\left(\mathrm{X}^{2} \mathrm{p}>0.05^{*}\right)$. In the category of fall and others, no less than $50 \%$ of patients had pre-existing illness (systemic arterial hypertension, Diabetes Mellitus II, Obesity, Smoking and alcoholism) as predisposition factors to factures. Not informed category, were those patients who were only diagnosed and treated in the Emergency Service but then subsequently discharged from hospital.

\section{Prevalence OP in Mexico}

From 32 medical records reviewed, no more than three percentage (one patient) was diagnosed with OP using BMD and only one patient received treatment for OP (data not shown). These results suggest the reliable diagnosis and timely treatment of fracture fragility and OP were not performed according to issued criteria by health entities as International Federation Osteoporosis (IFO) or WHO.

\section{Discussion}

The $97 \%$ of admitted orthopedic patients received medical management not according to criteria issued by health entities as IFO or WHO, related to reliable diagnosis and timely treatment of fracture fragility and OP. Probably this accounts why no more than one patient was diagnosed with OP using BMD and only one patient received treatment for OP (data not shown). Therefore it is recommended to initiate a campaign of awareness and training of the medical community, for treatment of fragility fractures and OP and implement preventive actions to avoid the cascade of fractures for benefit of patients. No significant statistical differences $\left(\mathrm{p}>0.05^{*}, \mathrm{X}^{2}\right.$ test) were found between the different distribution of gender studied, very probably due to lower number of patients in

Table 3. Distribution of gender according to trauma mechanism of orthopedic patients treated at the General Hospital $\mathrm{H}+$ in Queretaro Mexico, from January to December 2017

\begin{tabular}{|c|c|c|c|c|}
\hline \multirow{2}{*}{$\begin{array}{c}\text { Mechanism of } \\
\text { trauma }\end{array}$} & \multicolumn{2}{|c|}{ Male } & \multicolumn{2}{c|}{ Female } \\
\cline { 2 - 5 } Fall & $\mathbf{N}$ & $\%$ & $\mathbf{N}$ & $\%$ \\
\hline Car accident & 2 & 22.2 & 0 & 0 \\
\hline Others & 1 & 11.1 & 3 & 13 \\
\hline Not informed & 2 & 22.2 & 7 & 30.4 \\
\hline $\begin{array}{l}\text { Total } \\
\text { Font: medical records }\end{array}$ & 9 & 100 & 23 & 100 \\
\hline p>0.05* $\mathrm{X}^{2}$ test & & & \\
\hline
\end{tabular}


the sample in study. However, qualitative data showed that frequency of patients with the most common type and trauma mechanism of fractures admitted in the Orthopedic Service was consistently increased in female than male genders Tables 1-3; and these groups of results are congruent with previous reports by Johansson $\mathrm{H}$ et al. [2] and Clark et al. [3]. Hence, the more frequent factures in both gender reported in this study Table 2 are similar with that previously reported by Clark et al. [3] and the prevalence of fractures obtained in this study $(6 \%$ in male and $15 \%$ in female) was close to the percentages of prevalence (male 9.8\% - female 19.2\%) reported for vertebral fractures by Clark et al. [6,7]. Since the Mexican population is aging and its life expectancy increasing it is expecting the incidence of $\mathrm{OP}$ and fragility fractures associated to grow accordingly and to threat the Mexican health system in the near future [1]. This retrospective study shows intrinsic limitations related to the General Hospital $\mathrm{H}+$, as a private and general health institution, with approximately 150 patient presentation (at Emergency Service) in 2017 year, and not to be a specialized government health institution for orthopedic patients and medicine areas related with osteoarthritis and OP management.

\section{Conclusion}

A noticeable finding in this study in that does not exists a medical management of patients admitted in the Orthopedic Service from Hospital $\mathrm{H}+$, related to reliable diagnosis and timely treatment of fracture fragility and OP, according to issued criteria by IFO or WHO. Probably these conditions contributed importantly to the increased fragility fractures associated to the high risk group of adults and elderly and the absence of patients diagnosed with OP observed in this retrospective study.

The frequency of patients with the most common type and trauma mechanism of fractures admitted in the Orthopedic Service of General Hospital H+ was consistently increased in female group and these results are congruent with previous epidemiological reports in Mexico.
Increased fragility fractures and OP represent an imminent threat for the health system in the near future as Mexican population continues to aging and its life expectancy continues to increase [1].

The Regenerative Medicine Center from Queretaro Mexico invites to the Orthopedic Service of the General Hospital H+ for attending the campaign of awareness and training of the medical community according to issued criteria of IFO, as responsible for the treatment of fragility fractures and OP and to implement preventive actions to avoid a cascade of fractures for benefit of patients and for lowering of the high associated cost both in public and private institutions.

\section{References}

1. https://www.census.gov/data-tools/demo/idb/ informationGateway.php

2. Johansson $\mathrm{H}$, Clark $\mathrm{P}$, Carlos $\mathrm{F}$ et al. Increasing age- and sex-specific rates of hip fracture in Mexico: a survey of the Mexican institute of social security. Osteoporos. Int. 22(8), 2359-64 (2011).

3. Clark P, Carlos F, Vázquez-Martínez J. Epidemiology, costs and burden of OP in Mexico. Arch. OP. 5(1-2), 9-17 (2010).

4. Clark P, Lavielle P, Franco-Marina F et al. Incidence rates and life-time risk of hip fractures in Mexicans over 50 years of age: a population-based study. Osteoporos. Int. 16(12), 2025-30 (2005)

5. Maggi S, Kelesy JL, Litvak J et al. Incidence of hip fractures in the elderly: A cross-national analysis. Osteoporos. Int. 1(4), 232-41 (1991).

6. Clark P, Cons-Molina F, Delezé M et al. The prevalence of vertebral fractures in Latin American countries: The Latin-American Vertebral OP Study (LAVOS). Osteoporos. Int. 20(2), 275-82 (2009).

7. Clark P, Cons-Molina F, Deleze M et al. The prevalence of radiographic vertebral fractures in Mexican men. Osteoporos. Int. 21(9), 1523-1528 (2010).

8. Deleze M, Cons-Molina F, Villa AR et al. Geographic differences in bone mineral density of Mexican women. Osteoporos. Int. 11(7), 562-9 (2000).

9. Clark P, Delezé M, Cons-Molina F et al. Prevalencia de fracturas vertebrales en población Mexicana (abstract). Rev. Metab. Oseo. Min. 1, 41 (2003).

10. Clark P, Ragi S, Delezé M et al. The prevalence of low bone mineral density in a random sample of Mexican women and men 50 years and older. A population study. J. Clin. Densitom. 9(2), 234-236 (2006). 